\title{
Multidrug-Resistant Acinetobacter
}

\author{
Ashwini Vishwanth Jadhav* and Nasira Khalid Shaikh
}

VMGMC, Solapur, Maharashtra, India

*Corresponding author

\section{A B S T R A C T}

Keywords

Acinetobacter,

Extremely drug

resistant (XDR),

multidrug-resistant

(MDR), surgical site

infection (SSI), Pan-

drug resistant (PDR)

Article Info

Accepted:

19 July 2017

Available Online:

10 September 2017
Acinetobacter species has been increasingly reported as the cause of nosocomial infections and possess a serious threat to the health care system because of its multi-drug resistance. The present study was a prospective study carried out in the Department of Microbiology from August 2013 to November 2015 in a tertiary care hospital to isolate and speciate Acinetobacter species from clinical samples and to determine their antibiogram. 150 clinical isolates of Acinetobacter species were processed for species identification and antimicrobial susceptibility of these isolates was performed by Kirby-Bauer disc diffusion method. Out of 150 Acinetobacter isolates, 94(62.67\%) were extensively drug resistant, 18 (12\%) were multi-drug resistant and 15(10) of the isolates were pan-drug resistant. Proper application of infection control measures and antibiotic stewardship is necessary in order to combat this problem

\section{Introduction}

Acinetobacter species has emerged as one of the most troublesome pathogens in the in the healthcare setting both globally and locally.

Its remarkable ability to develop or acquire multiple antibiotic resistance and propensity to survive for prolonged periods under a wide range of environmental conditions, make it a frequent cause of hospital outbreaks and an endemic healthcare associated pathogen.

It commonly targets the most vulnerable hospitalised and critically ill patients with breaches in skin integrity who require airway protection, causing pneumonia, urinary tract infection, wound infection and bacteremia (Tak-chiu, 2011).
Control of hospital acquired infection caused by multi resistant gram negative bacteria by using broad spectrum antibiotics in hospital has subsequently resulted into increased into infection by gram negative bacteria like Pseudomonas aeruginosa, Stenotrophomonas maltophilia and Acinetobacter species (Bergogne-Berezin et al., 1996). Among these pathogens Acinetobacter species play a significant role in colonisation and infection of patients admitted in hospital. Where they have been implicated in a variety of nosocomial infections like bacteraemia, urinary tract infection, secondary meningitis, ventilator associated pneumonia and wound infections (Bergogne-Berezin, 1987; French et al., 1980). Among the various risk factors 
for colonisation and infection exposure to Carbapenems, broad spectrum antibiotics is most common factor for acquisition of drug resistance in Acinetobacter (Gaur et al., 2007).

Now a day Acinetobacter are revealing resistance to most commonly used antibiotics. They are now becoming Multi-resistant (MDR). Acinetobacter resistant to any three classes from third generation Cephalosporins, Penicillins, Aminoglycosides and Fluroquinolones are considered as Multi-drug resistant (MDR) while in addition to this if Carbapenem resistant isolates is also noted considered as Extensively drug resistant (XDR) (Manchanda, 2010).

Acinetobacter resistant to all antimicrobial drug used including Colistin and Tigecycline considered to be Pan drug resistant (PDR). Emergence of drug resistance limits therapeutic options for effective treatment.

\section{Materials and Methods}

The present study was conducted in the department of Microbiology. Wound swab, pus samples were collected from the patients of post-operative wound infections.

\section{Sample collection}

Pus/ Exudate was collected from deeper part of the wound with the help of two sterile swab sticks in sterile test tube and transported immediately to laboratory.

Identification of Acinetobacter species was done by using standard laboratory methods.

\section{Antibiotic susceptibility testing}

All the bacterial isolates were subjected to antibiotic susceptibility testing by Kirby Bauer disc diffusion technique (Winn,
2006) (Figure 1).

Since CLSI guidelines for Colistin disc diffusion are not available for Acinetobacter species so we used Pseudomonas aeruginosa CLSI 2013 guidelines (CLSI 2013). Standard strains of E. coli (ATCC- 25922), Pseudomonas aeruginosa (ATCC-27853) were used as controls.

\section{Antibiotics used}

Commercially available antibiotic disks obtained from Hi- Media Laboratories Ltd, were used. Antibiotics used were Piperacillin $(100 \mu \mathrm{g})$, Ampicillin $(30 \mu \mathrm{g})$, Ceftazidime $(30 \mu \mathrm{g})$, Ceftriaxone $(30 \mu \mathrm{g})$, Cefepime $(30 \mu \mathrm{g})$, Ampicillin-sulbactum $(10 / 10 \mu \mathrm{g})$, Imipenem $(10 \mu \mathrm{g})$, Amikacin $(30 \mu \mathrm{g})$, Ciprofloxacin $(5 \mu \mathrm{g})$ and Colistin $(10 \mu \mathrm{g})$

\section{Results and Discussion}

Total 150 isolates were tested for antibiotic resistant. According to their resistance pattern they are labelled as MDR, PDR and XDR as per definitions. Antibiotic sensitivity pattern of 150 Acinetobacter isolates is as shown in table 1.

As per the definition of MDR Acinetobacter $12 \%$ were MDR,62.67\% strains were also resistant to Carbapenem along with MDR so considered as XDR and $10 \%$ strain were resistant to all antibiotic including Tigecycline and Colistin considered as PDR (Figure 2).

Acinetobacter exhibited varying degree of resistance to antibiotics. In spite of being on antibiotic prophylaxis if the patient is developing wound infection, the probability of the isolating Acinetobacter species with drug resistance is more. In Acinetobacter wound infection, it is likely to become Multidrug resistant (MDR) or Extensive drug 
resistant (XDR) or Pan-drug resistant (PDR) upon prior antibiotic use (Table 2).

In present study, Acinetobacter species were resistant to Ampilcillin $\mathrm{n}=144$ (94\%) followed by Ciprofloxacin $n=140$ (93.33\%).

In Cephalosporins maximum number of isolates were resistant to Cefepime $\mathrm{n}=132$ $(86.67 \%)$ followed by Ceftriaxone $\mathrm{n}=127$ $(84.67 \%)$ followed by Ceftazidime $n=125$ (82.67\%).Amikacin resistance was $\mathrm{n}=125$ $(82 \%)$.

In present study resistant to Carbapenem is high, viz.to Imipenem was $78 \%$ and Meropenem was $76.67 \%$. Colistin was found to be most susceptible antibiotic as 127 $(84.67 \%)$ were susceptible. followed by Thirty six isolates $(24 \%)$ were sensitive to
Ampi-sulbactum. Result of present study correlate with many other studies.

Gaur et al., (2008) study from north India showed similar results. In their study antibiotic susceptibility testing was done by disc diffusion method. Acinetobacter isolates revealed $80 \%$ resistance to third generation Cephalosporins and in Quinolones, $81 \%$ were resistant to Ciprofloxacin. Among Aminoglycosides, $74 \%$ were resistant to Amikacin (Gaur et al., 2008)

A study from south India showed high resistance to Ampicillin (86.8 \%) which is similar to present study. In their study Ceftazidime (74.5\%), Amikacin (51.6\%), Gentamicin (60.6\%), and Ciprofloxacin (69.6 \%) (Sivaranjani, 2013).

Table.1 Antibiotic sensitivity pattern of Acinetobacter isolates by disc diffusion and agar dilution

\begin{tabular}{|c|c|c|c|c|c|}
\hline \multirow[t]{3}{*}{ Sr no } & \multirow[t]{3}{*}{ Antibiotic $(\mu \mathrm{g})$} & \multicolumn{4}{|c|}{ Disc diffusion $(\mathrm{n}=150)$} \\
\hline & & \multicolumn{2}{|c|}{ Sensitive } & \multicolumn{2}{|c|}{ Resistant } \\
\hline & & No of strains & $\begin{array}{c}\text { Per-centage } \\
(\%)\end{array}$ & No of strains & $\begin{array}{c}\text { Per-centage } \\
(\%)\end{array}$ \\
\hline 1 & Ampicillin & 6 & 4 & 144 & 94 \\
\hline 2 & Ceftrixone & 23 & 15.33 & 127 & 84.67 \\
\hline 3 & Ceftazidime & 25 & 16.67 & 125 & 83.33 \\
\hline 4 & Cefepime & 18 & 12 & 132 & 88 \\
\hline 5 & Ampi-sulbactum & 36 & 24 & 114 & 76 \\
\hline 6 & Ciprofloxacin & 10 & 6.67 & 140 & 93.67 \\
\hline 7 & Imipenem & 26 & 17.33 & 124 & 82.67 \\
\hline 8 & Colistin & 124 & 82.67 & 26 & 17.33 \\
\hline 9 & Amikacin & 25 & 16.67 & 125 & 83.67 \\
\hline
\end{tabular}

Table.2 MDR, XDR and PDR distribution of Acinetobacter isolates

\begin{tabular}{|l|l|l|l|}
\hline & MDR & XDR & PDR \\
\hline Total no of strain & 18 & 94 & 15 \\
\hline Percentage & 12 & 62.67 & 10 \\
\hline
\end{tabular}


Fig.1 Antibiotic screening test by Kirby Bauer method

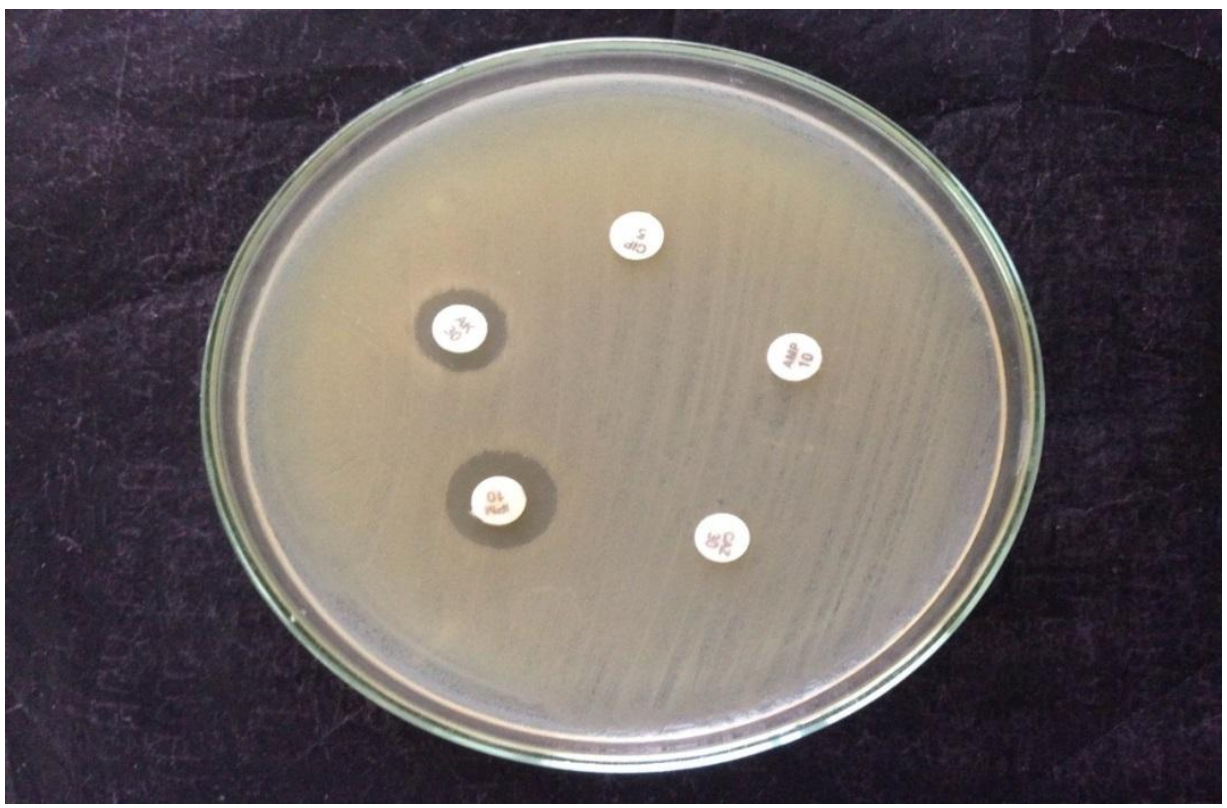

Fig.2 MDR, XDR and PDR distribution of Acinetobacter isolates

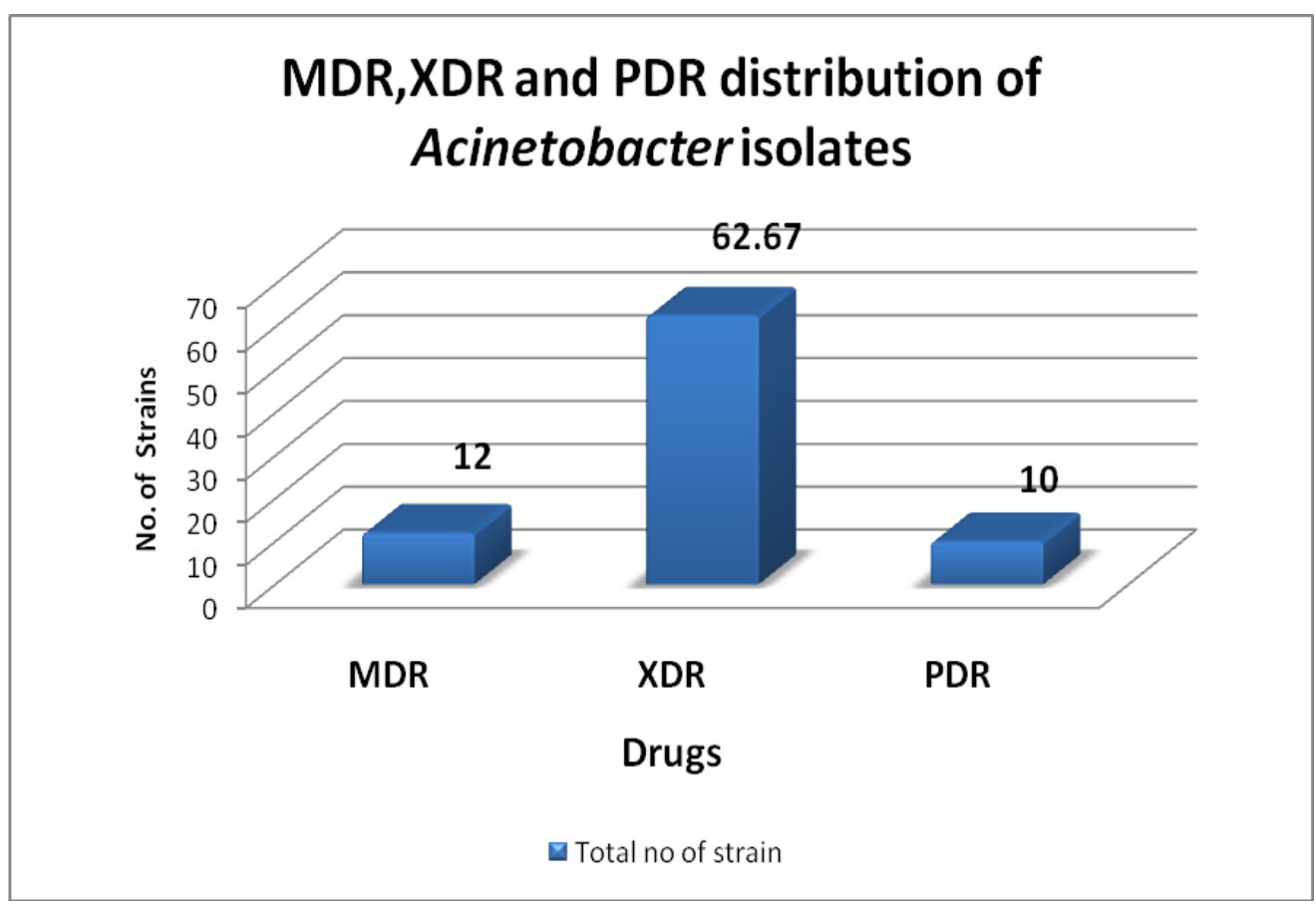

Another study of Fatma et al., (2014) showed high resistance of Acinetobacter species to different classes of antibiotics. She also reported high resistant to different generation of Cephalosporins viz. 88.3\% of isolates were resistant to Ceftazidime and Ceftriaxone, $90 \%$ to Cefotaxime, $91.7 \%$ to Cefepime. Resistance to other classes of drug was $96.7 \%$ Ampicillin/sulbactam, 76.7 to Amikacin, 86.7 to Ampicillin and $75 \%$ Ciprofloxacin. This correlates with present study (Al-Zahraa, 2014). 
In Rahul Kamble study (2015), 98.84\%, Acinetobacter species were resistant to Ceftriaxone, $98.26 \%$ to Ceftazidime, $94.35 \%$ to Cefepime, $79.7 \%$ to Ciprofloxacin and $72 \%$ to Amikacin (Rahul Kamble study, 2015).

In Sana Islahi study (2014), $>80 \%$ of Acinetobacter isolates were resistant to Amikacin, Gentamycin, Ceftriaxone, Ciprofloxacin and Tetracycline (Sana Islahi study, 2014). These results are similar to present study. Whereas resistant to colistin was $19.56 \%$.

In Shrestha et al., (2008) study, resistance to Amikacin and Gentamycin was low (51\%) as Aminoglycosides used as reserved drug for Acinetobacter infection and mostly in combination with Cephalosprins (Shrestha et al., 2008).

Acinetobacter resistant to any three classes from third generation Cephalosporins, Penicillins, Aminoglycosides and Fluroquinolones are considered as Multi-drug resistant (MDR) while in addition to this if Carbapenem resistant isolates is also noted considered as Extensively drug resistant (XDR). Acinetobacter resistant to all antimicrobial drugs used including Colistin and Tigecycline considered to be Pan drug resistant (PDR) (Mnachanda et al., 2010). In present study, $12 \%$ isolates were MDR, 62.67 $\%$ isolates were XDR and $10 \%$ were PDR. Carbapenem are the drug of choice for MDR Acinetobacter infection so their use is increased now days, so recently we came across with XDR Acinetobacter in hospitals. Our observations are consistent with Rahul Kamble (2015) study from Mumbai (Rahul Kamble, 2015). He noticed $14 \%$ isolates were MDR and 58\% Isolates were XDR. No PDR isolates were found in their study.

Inchai Juthamas et al., (2015) observed MDR were $<20 \%$, XDR $65.3 \%$ and $3.6 \%$ PDR
Acinetobacter. Japoni-Nejad A. et al., (2013) noticed $11 \%$ PDR and $89 \%$ XDR Acinetobacter. In their study more number of XDR could be due to small study group and samples mainly from seriously ill patients where Carbapenem use is frequent (Inchai Juthamas et al., 2015; Japoni-Nejad et al., 2013).

Acinetobacter species is emerging as an opportunistic pathogen which causes numerous infections in hospitalised patients. As a result of alarming increase in its drug resistance, it seems that nowadays we left with very few options of antibiotic to treat it. Furthermore, the inconsistencies in defining multidrug resistance in this pathogen have caused considerable confusion to both clinicians and researchers. One way to circumvent this is to have proper definitions for terms like MDR, XDR and PDR through surveillance programmes.

\section{Acknowledgement}

Authors acknowledge department staff for their help and also to the authors whose articles are cited in this manuscript.

\section{References}

Al-Zahraa, F.M.G., Tawakol WM, El-Azm FIA. 2014. Phenotypic and genotypic detection of some antimicrobial resistance mechanisms among multidrug-resistant Acinetobacter baumannii isolated from immune compromised patients in Egypt. Egyptian Journal of Medical Microbiology. 23(4): 99-111.

Bergogne-Berezin, E., Joly-Guillou M L, Vieu J F. 1987. Epidemiologyof nosocomial infections due to Acinetobacter calcoaceticus. J. Hosp. Infect., 10:105113.

Bergogne-Berezin, E., Towner K J.Apr.1996. Acinetobacter spp. As Nosocomial Pathogens: Microbiological, Clinical, and Epidemiological Features. Clinical 
Microbiolog Reviews. 9(2): 148-165.

French, G., Casewell M, Roncoroni A, Knight S, Phillips I.1980. A hospital outbreak of antibiotic-resistant Acinetobacter anitratus: epidemiology and control. Journal of Hospital Infection. 1(2):125131.

Gaur, A., Bhattacharjeew A, Anupurba S. 2007. Clinic significance and epidemiology of multidrug Resistant Acinetobacter species isolated from Nosomial infection. Indian J. Prev. Soc. Med. 38(1\&2): 5-9.

Gaur, A., Garg A, Prakash P, Anupurba S, Mohapatra TM. Jun 2008. Observations oncarbapenem resistance by minimum inhibitory concentration in nosocomial isolates of Acinetobacter species: an experience at a tertiary care hospital in North India. J Health Popul. Nutr. 26(2): 183-8.

Inchai, J., Pothirat C, Bumroongkit C,Limsukon A, Khositsakulchai W, Liwsrisakun C. 2015. Prognostic factors associated with mortality of drug resistant Acinetobacter baumannii ventilator-associated pneumonia. Journal of Intensive Care. 3(1): 9.

Islahi, S., Ahmad F, Khare V, Mishra N, Yaqoob S, Shukla P et al., 2014. Prevalence and Resistance Pattern of Acinetobacter Species in Hospitalized Patient's in A Tertiary Care Centre. Journal of Evolution of Medical and Dental Sciences. 3(17): 4629-4635.

Japoni-Nejad, A., Sofian M, Belkum A, Ghaznavi-Rad E. 2013. Nosocomial Outbreak of Extensively and Pan DrugResistant Acinetobacter baumannii in Tertiary Hospital in Central Part of Iran.
Jundishapur J Microbiol. 6(8).

Manchanda, V., Sinha S, Singh N. 2010. Multidrug resistant Acinetobacter. Journal of Global Infectious Diseases. 2(3): 291.

Performance Standards for Antimicrobial Susceptibility Testing; Twenty-Third Informational Supplement. CLSI Document M100-S23.Wayne, PA: Clinical and Laboratory Standards Institute; 2013.

Rahul Kamble, 2015. Acinetobacter species in Health Care setting: Clinical significance and Antimicrobial sensitivity. Int. J. Curr. Microbiol. App. Sci., 4(4): 861-869.

Shrestha, M., Khanal B. 2013. Acinetobacter Species: Phenotypic Characterization and Antimicrobial Resistance. Journal of Nobel Medical College. 2(1):43-48.

Sivaranjani, V., Umadevi S, SrirangarajS, Kali A, Seetha K. 2013. Multi-drug resistant Acinetobacter species from various clinical samples in a tertiary care hospital from South India. The Australasian Medical Journal. 6(12): 697-700. doi:10.4066/AMJ.2013.1901. http://doi.org/10.4066/AMJ.2013.1901

Tak-chiu, W.U., APRIL 2011, Carbapenemresistant or Multidrug-resistant Acinetobacter Baumannii - a Clinician's Perspective. The Hongkong Medical Diary. 16(4): 6-9.

Winn, W.C., Allen SD, Janda WM, Koneman EW, Procop GW, Schreckenberger PC, Woods GL editors. 2006. Antimicrobial susceptibility testing Colour atlas and textbook of diagnostic Microbiology, $6^{\text {th }}$ ed. Philadelphia: Lippincott Williams and Wilkins. Pp. 947-1015.

\section{How to cite this article:}

Ashwini Vishwanth Jadhav and Nasira Khalid Shaikh. 2017. Multidrug-Resistant Acinetobacter. Int.J.Curr.Microbiol.App.Sci. 6(9): 1598-1603.

doi: https://doi.org/10.20546/ijcmas.2017.609.196 